C. ВНЛКОВА, Серафима АРТЕМЕНКО, М. ТЮГАНОВА,

удК $678.01+677.4 .017 .56$ Айли КОГЕРМАН, О. КИРРЕТ, Э. ХЕИНСОО

\title{
ВЛИЯНИЕ ХИМИЧЕСКОГО СОСТАВА АНТИПИРЕНА В ОГНЕЗАЩИЩЕННЫХ ВИСКОЗНЫХ ВОЛОКНАХ НА СВОЙСТВА КОМПОЗИЦИОННЫХ МАТЕРИАЛОВ
}

Установлено [1-5], что огнезащищенные вискозные волокна, применяемые в качестве армирующей системы, эффективно ингибируют горение композиционных материалов (KM).

Значительный вклад в химию и технологию модифицирования химических волокон с целью придания им огнестойкости внес 3. А. Poroвин [6]. Однако вопросы влияния строения антипиренов и механизма разложения ими химических волокон изучены недостаточно. В стадии разработки находятся также вопросы придания КМ негорючести путем армирования огнезащищенными волокнами [].

В данной работе изучен ряд огнезащищенных тканей (ОЗТ) вискозных волокон с антипиренами различного химического состава, оценена их способность к снижению горючести и дымообразования, а также определены физико-механические свойства КМ.

Для модификаций вискозной ткани (или волокна) использовали: 1) диаммонийдиводороддифосфат $\left(\mathrm{NH}_{4}\right)_{2} \mathrm{H}_{2} \mathrm{P}_{2} \mathrm{O}_{7}$ (О3Т-1); 2) трикрезилфосфат $\left(\mathrm{CH}_{3} \mathrm{C}_{6} \mathrm{H}_{4} \mathrm{O}\right)_{3} \mathrm{PO}$ (О3Т-2): 3) антипирен M-1 (O3Т-3) и 4) диамидометилфосфонат $\mathrm{CH}_{3} \mathrm{PO}\left(\mathrm{NH}_{2}\right)_{2}$ с хлористым аммонием (О3Т-4). Антипирены вводили, пропитывая ткани (волокна) их $7-20 \%$-ными водными растворами при комнатной температуре до $2,5-3 \%$-ного содержания фосфора на сухой ткани. В качестве сшивающих агентов использовали мочевину или раствор формалина; термообработку вели при $130-140^{\circ} \mathrm{C}$ в течение 5-10 мин. В качестве связующего использовали эпоксидную смолу ЭД-20, отверждаемую полиэтиленполиамином (1:10 по массе). КM, армированные вискозными тканями или волокнами в виде холста, получали способом прессования при $90^{\circ}$ и давлении 8-10 МПа с дополнительной термообработкой в течение 2 ч при $100^{\circ}$.

Горючесть оценивали по кислородному индексу (КИ), потерям массы по методике «Огневая труба» и дымообразованию в камере, описанной в $\left.{ }^{4}\right]$.

В связи с -тем, что процесс горения тесно связан с процессом деструкции полимерных материалов, изучали термоокислительную деструкцию огнезащищенных тканей и КМ на их основе методом термогравиметрического анализа на дериватографе при скорости нагревания $10 \%$ мин, навеска 200 мг. Количественный состав газообразных продуктов пиролиза волокон и КМ определяли методом ступенчатой пиролизной газовой хроматографии (СПГХ) в токе гелия при длительности экспозиции 15 с и повышении температуры через каждые $10^{\circ}\left[{ }^{7}\right]$.

У всех ОЗТ проявляются при деструкции общие закономерности, вне зависимости от состава антипиренов: максимальная температура 


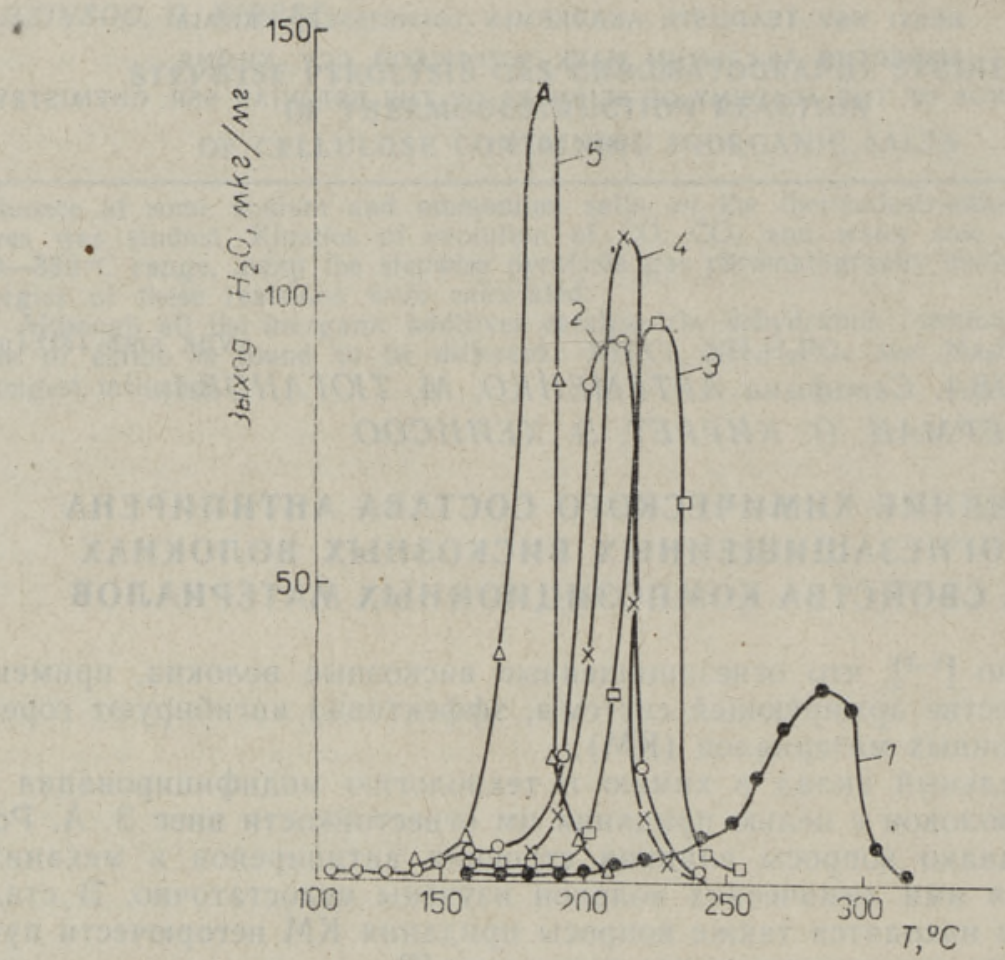

Рис. 1. Выход воды при пиролизе вискозной ткани (I), О3Т-1 (2), ОЗТ-3 с раз. личным количеством антипирена $\mathrm{M}-1(3,4)$ и ОЗТ-4 (5).

основной стадии деструкции ОЗТ снижается, температурный интервал разложения сужается и потери массы уменьшаются по сравнению с теми же показателями для исходной вискозной ткани (табл. 1). При: чем температура начала стадии термического разложения неоднознач-

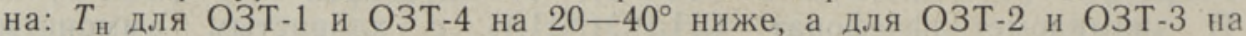
$10^{\circ}$ выше, чем для немодифицированной ткани. По-разному ведут себл О3Т и при более высоких температурах, в области полной потерн массы. Так, для О3Т-2 при температурах выше $450^{\circ}$ потери массы больше, чем у вискозной ткани, и температура полной потери массы самая низкая. Для О3Т-3 и О3Т-4 характерны большой углеродный остаток и высокая температура полной потери массы. Эти ткани имеют

Таблица I

Термогравиметрический анализ вискозных тканей, модифицированных различными по строению антипиренами

\begin{tabular}{|c|c|c|c|c|c|c|c|c|}
\hline \multirow[b]{2}{*}{$\begin{array}{l}\text { Мате- } \\
\text { риал }\end{array}$} & \multicolumn{4}{|c|}{$\begin{array}{c}\text { Показатели основной стадии } \\
\text { деструкции }\end{array}$} & \multirow{2}{*}{ 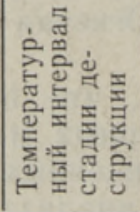 } & \multirow{2}{*}{ 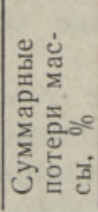 } & \multirow{2}{*}{ 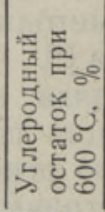 } & \multirow{2}{*}{ 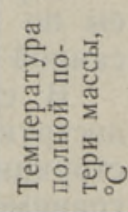 } \\
\hline & $\begin{array}{c}T_{\mathrm{H}}-T_{\mathrm{Ma \kappa c}}, \\
{ }^{\circ} \mathrm{C}\end{array}$ & $\begin{array}{c}\text { По- } \\
\text { тери } \\
\text { массы, } \\
\%\end{array}$ & $T_{\text {макс }}{ }^{\circ} \mathrm{C}$ & $\begin{array}{c}\text { По- } \\
\text { терн } \\
\text { массы, } \\
\%\end{array}$ & & & & \\
\hline $\begin{array}{l}\text { Вискоз- } \\
\text { ная ткань }\end{array}$ & $210-312$ & 49 & $312-360$ & 8 & 150 & 57 & 10 & 675 \\
\hline $\begin{array}{l}\text { O3T-1 } \\
\text { O3T- } 2 \\
\text { O3T-3 } \\
\text { O3T-4 }\end{array}$ & $\begin{array}{l}170-250 \\
220-300 \\
220-260 \\
190-240\end{array}$ & $\begin{array}{l}40 \\
23 \\
27 \\
24\end{array}$ & $\begin{array}{l}250-280 \\
300-330 \\
260-300 \\
240-280\end{array}$ & $\begin{array}{r}15 \\
15 \\
4 \\
14\end{array}$ & $\begin{array}{r}110 \\
110 \\
80 \\
90\end{array}$ & $\begin{array}{l}55 \\
38 \\
31 \\
38\end{array}$ & $\begin{array}{r}17 \\
4 \\
26 \\
25\end{array}$ & $\begin{array}{l}740 \\
630 \\
900 \\
900\end{array}$ \\
\hline
\end{tabular}


наилучшие с точки зрения огнезащиты характеристики: пониженные на $50-70^{\circ}$ температуры основной стадии термической деструкции и повышенный на 15-16\% выход углеродного остатка.

По данным СПГХ, дегидратация вискозных волокон в присутствии антипиренов сдвигается на $50-100^{\circ}$ в сторону более низкой температуры и протекает с бо́льшим по сравнению с немодифицированной тканью выходом воды (рис. 1). При этом наибольшее количество воды выделяется при пиролизе ОЗТ-3 и ОЗТ-4, что и обусловливает их меньшую горючесть (табл. 2).

Однако эффект модифицирования вискозного волокна может снижаться в композиции со связующим. Это отмечено для антипирена M-1 (табл. 3), который снижает горючесть вискозного волокна, но в композиции со связующим его эффективность понижается. Модифицированные волокна ОЗТ-1 и О3Т-4 в композициях со связующим прояв-

Таблица 2

Данные ступенчатой пиролизной газовой хроматографии вискозных материалов и КМ на их основе

\begin{tabular}{|c|c|c|c|c|c|c|c|}
\hline \multirow{2}{*}{ Материал } & \multirow[b]{2}{*}{ КИ } & \multicolumn{2}{|c|}{$\mathrm{H}_{2} \mathrm{O}$} & \multicolumn{2}{|c|}{$\mathrm{CO}_{2}$} & \multicolumn{2}{|c|}{$\mathrm{CO}$} \\
\hline & & $\mathrm{MKF} / \mathrm{Mr}$ & $T_{\text {макс, }}{ }^{\circ} \mathrm{C}$ & $\mathrm{MKr} / \mathrm{Mr}$ & ${ }_{{ }^{\circ} \mathrm{C}}$ & MKг/MГ & $T_{\text {макс, }}$ \\
\hline $\begin{array}{l}\text { Вискозная ткань } \\
\text { О3Т-1 } \\
\text { О3Т-3a } \\
\text { О3Т-36 } \\
\text { О3Т-4 }\end{array}$ & $\begin{array}{l}22,0 \\
46,5 \\
41,0 \\
49,5 \\
57,0\end{array}$ & $\begin{array}{l}151,3 \\
214,9 \\
215,0 \\
192,3 \\
228,6\end{array}$ & $\begin{array}{l}282 \\
206 \\
223 \\
210 \\
180\end{array}$ & $\begin{array}{r}128,6 \\
145,8 \\
72,8 \\
59,4 \\
62,8\end{array}$ & $\begin{array}{l}283 \\
200 \\
225 \\
210 \\
180\end{array}$ & $\begin{array}{r}57,7 \\
7,4 \\
18,8 \\
15,0 \\
2,8\end{array}$ & $\frac{280}{-}$ \\
\hline
\end{tabular}

Композиционные матери алы

Вискозная ткань / ЭД-20

ОЗТ -3/ЭД-20a

О3Т-3/ЭД-20б

О3Т- $4 / Э Д-20$

\begin{tabular}{l|l|l}
22,0 & 203,0 & 290 \\
28,5 & 211,6 & 245 \\
33,0 & 207,4 & 240 \\
41,0 & 209,0 & 175
\end{tabular}

\begin{tabular}{l|l}
69,3 & 290 \\
72,2 & 255 \\
70,7 & 240 \\
71,0 & -
\end{tabular}

85,7
89,3
87,5
88,0

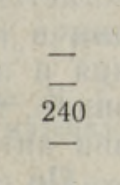

Таблица З

Свойства композиционных материалов, армированных огнезащищенными вискозными волокнами

\begin{tabular}{|c|c|c|c|c|c|c|c|c|c|}
\hline \multirow[b]{2}{*}{ 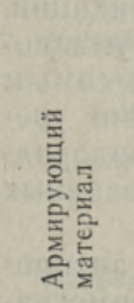 } & \multirow[b]{2}{*}{ 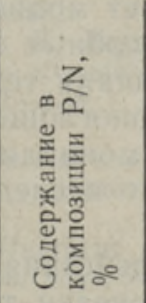 } & \multirow[b]{2}{*}{$\stackrel{*}{\Sigma}$} & \multirow[b]{2}{*}{ 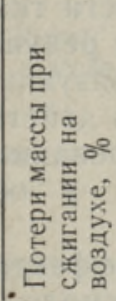 } & \multicolumn{2}{|c|}{$\begin{array}{l}\text { Дымообра- } \\
\text { зование }\end{array}$} & \multicolumn{3}{|c|}{$\begin{array}{l}\text { Изменение физико- } \\
\text { механических пока- } \\
\text { зателей, \% от исх. }\end{array}$} & \multirow[b]{2}{*}{ 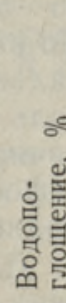 } \\
\hline & & & & 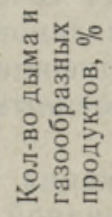 & 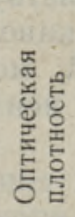 & 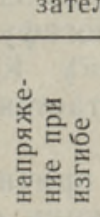 & 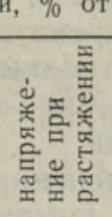 & 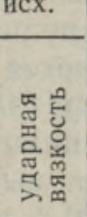 & \\
\hline $\begin{array}{l}\text { Вискоз- } \\
\text { ная ткань } \\
\text { О3Т-1 } \\
\text { О3Т-2 } \\
\text { O3Т-3 } \\
\text { О3Т-4 }\end{array}$ & $\begin{array}{c}1,24 / 5,15 \\
1,05 / 2,30 \\
1,00 / 3,35 \\
1,17 / 3,01\end{array}$ & $\begin{array}{l}22,0 / 22,6 \\
36,1 / 32,5 \\
33,5 / 33,0 \\
28,5 / 32,1 \\
39,0 / 37,2\end{array}$ & $\begin{array}{r}86 \\
12,5 \\
9,8 \\
73,3 \\
9,0\end{array}$ & $\begin{array}{l}77,6 \\
60,9 \\
64,5 \\
84,1 \\
65,8\end{array}$ & $\begin{array}{l}1,23 \\
0,45 \\
1,1 n \\
1,45 \\
0,64\end{array}$ & $\begin{array}{l}-15 \\
-17 \\
+52 \\
-10\end{array}$ & $\begin{array}{l}-10 \\
-50 \\
+5 \\
-10\end{array}$ & $\begin{array}{l}-15 \\
+38 \\
+45 \\
+25\end{array}$ & $\begin{array}{r}3,8 \\
10,1 \\
3,5 \\
3,6 \\
3,7\end{array}$ \\
\hline
\end{tabular}

* Данные в знаменателе рассчитаны исходя из количества отдельных компонентов и аддитивности нх свойств (для әпоксидной смолы ЭД-20 КИ=22). 


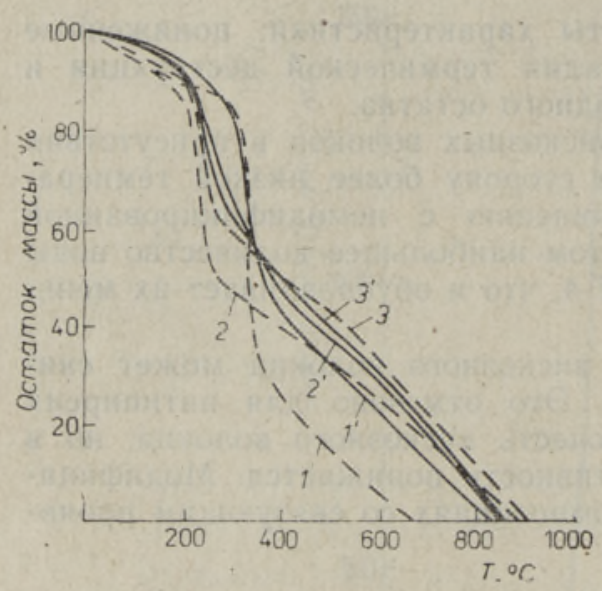

Рис. 2. Потери массы вискозного волокна (I) и КМ на его основе $\left(I^{\prime}\right)$, О3Т-4 и $\mathrm{KM}\left(2,2^{\prime}\right)$, О3Т-3 и $\mathrm{KM}\left(3,3^{\prime}\right)$ по данным термогравиметрического анализа.

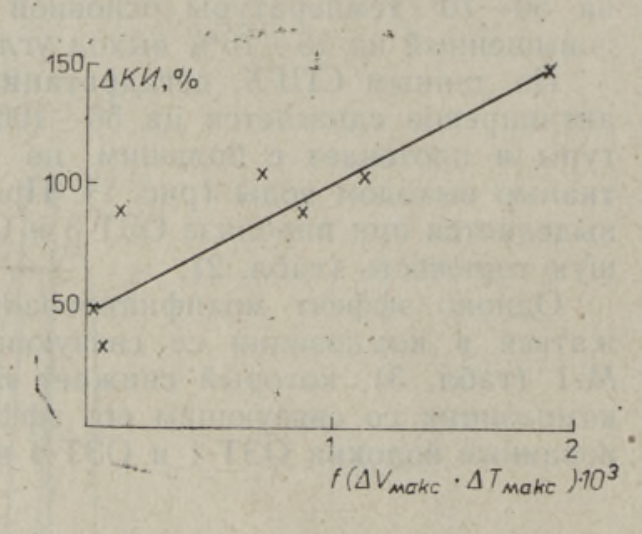

Рис. 3. Взаимосвязь КИ с показателями стадии дегидратации материалов на основе огнезащищенных вискозных во. локон.

ляют синергический эффект. Такие результаты свидетельствуют, что устойчивость к горению КМ определяется не столько огнестойкостью отдельных компонентов, сколько их взаимным влиянием.

Подтверждают сказанное и данные по дымообразованию КМ. Модификация вискозной ткани фосфоразотсодержащими соединениями состава О3Т-1, О3Т-2 и ОЗТ-4 приводит к заметному снижению дымообразования и оптической плотности дыма при сгорании КМ. Это свндетельствует о том, что большая часть карбонизированного углерода остается в коксовом остатке, а меньшая уносится продуктами деструкции в газовую фазу. Для систем с ОЗТ-3 показатели -дымоุобразования и плотности дыма выше, чем для немодифицированной композиции, т. е. зависят они от механизма пиролиза материалов в присугст. вии антипирена.

По основным показателям - разрушающему напряжению при изгибе и растяжении - свойства КМ ухудшаются вследствие сниження прочнисти вискозной ткани в результате модификации (разрывная нагрузка снижается на $10-35 \%)$. Исключение составляют КМ на основе ОЗТ-3, их прочность при изгибе и ударная вязкость возрастают на $45-50 \%$, несмотря на снижение прочности ткани за счет модификации. По-видимому, антипирен M-1, имеющий реакционноспособные функциональные группы, взаимодействует со связующим, выполняя тем самым роль антипирена многофункционального действия. Водопоглощение увеличивается только у КМ, модифицированных диаммонийдиводороддифосфатом, и остается неизменным у остальных исследованных модификаций.

Для выяснения причин снижения эффективности действия антипирена M-1 в композиции с эпоксидной смолой был проведен термогравиметрический анализ различных по горючести КМ: на основе немодифицированного вискозного волокна и модифицированных M-1 (О3Т-3) и диамидометилфосфонатом (ОЗТ-4). Результаты анализа показывают, что в области температур выше $400^{\circ}$ потери массы у KM на основе О3Т-4 заметно меньше, а у КМ на основе О3Т-3 значительно больше, чем у армирующего волокна (рис. 2).

О различном механизме действия антипиренов в волокне и КМ свидетельствуют результаты СПГХ (табл. 2). Как видно, действие фос- 
форазотсодержащих соединений в волокне проявляяется в снижении температуры дегидратации, повышении выхода воды и снижении содержания горючего газа СО. Для $\mathrm{KM}$ не отмечается изменений выхода $\mathrm{H}_{2} \mathrm{O}$ и $\mathrm{CO}$, снижается лишь температура дегидратации по сравнению c. KM на основе исходной ткани. В общем случае прослеживается корреляция между изменениями $\Delta K И$, выходом воды $\Delta V_{\text {макс и }} \Delta T_{\text {макс }}$ дегидратации (рис. 3). При пиролизе эпоксидных композиций, содержащих О3Т-4 и немодифицированную ткань, $\Delta T_{\text {макс дегидратации }}$

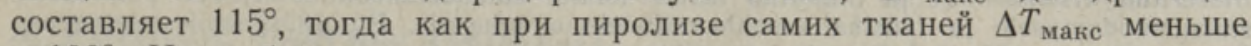
$-100^{\circ}$. И наоборот, при пиролизе эпоксидных композиций, содержа-

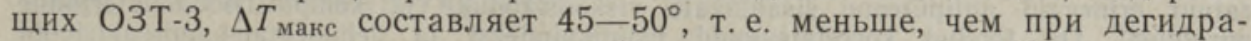

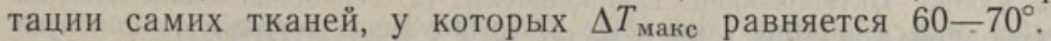

Это значит, что антипирен с диамидометилфосфонатом эффективен как в волокне, так и в КМ на его основе, а действие антипирена $M-1$ в композиции со связующим значительно подавляется по сравнению с его влиянием на пиролиз вискозного волокна, что и сопровождается незначительным повышением огнестойкости таких $\mathrm{KM}$ - ҚИ снижается до $28,5-33,0$, а потери массы возрастают до $73 \%$ (табл. 3). Поэтому для придания огнестойкости КМ с ОЗТ требуется применение антипиренов многофункционального действия, эффективных как на волокне, так и в композициях со связующим. Из исследованных наиболее перспективна вискозная ткань (волокно), модифицированная диамидометилфосфонатом, который при содержании $2,87 \%$ Р и $6,10 \% \mathrm{~N}$ придает КМ повышенную ударо- и огнестойкость.

\section{ЛИТЕРӒТ У РА}

1. Вилкова С. А., Артеменко С. Е., Тюганова М. А., Роговин З. А. Трудносгораемыс армированные полимерные материалы. - Пластмассы, 1978, № 5, 23-25.

2. Вилкова C. А., Артеменко C. E., Халтуринский H. А. Влияние огнезащищенных волокон на горение композиционных матерналов. - Высокомолекул. соединения, 1983, Б25, № 4, 276-277.

3. Артеменко С. Е., Вилкова С. А., Тюганова М. А., Халтуринский Н. А., Роговин 3. А. Авт. свид. № 697531, - Бюл. изобр., 1979, № $42,43$.

4. Вилкова С. А., Панова Л. Г., Вилков В. А., Артеменко С. Е., Вилесова М. С. Влияние ингибиторов на процесс горения полиакрилонитрильных материалов. - Ж. прикл. хим., 1983, № 5, 1107-1111.

5. Вилкова С. А., Артеменко С. Е., Лалаян В. М., Халтуринский Н. А., Берлин Ал. Ал., Когерман А. Р., Хейнсоо Э. Ю., Крулль М. А. Исследование влияння огнезащищенных вискозных тканей на процесс горения эпоксидных органопластиков. - Высокомолекул. соединения, 1980, А22, № 5, 1071-1077.

6. Тюганова M. А., Копьев М. А., Кочаров С. А. Огнезащищенные текстильные материалы. - Ж. Всесоюз. хим. Ч-ва им. Д. И. Менделеева, 1981, 26, № 4, $61-68$.

7. Heinsoo, E., Kogerman, A., Kirret, O., Coupek, J., Vilkova, S. Stepwise pyrolysisgas chromatography of viscose fibres. - J. Anal. Appl. Pyrol., 1980, 2, N 2, $131-139$.

Саратовский политехнический институт

Ннститут химии

Академии наук Эстонской ССР
Поступила в редакцию 15/XII 1983 
S. VILKOVA, Serafima ARTJOMENKO, M. TJUGANOVA, Aili KOGERMAN,

O. KIRRET, E. HEINSOO

\section{SUTTIMISKINDLATES VISKOOSKIUDUDES SISALDUVA ANTIPOREENI KEEMILISE KOOSTISE MÕU KOMPOSITSIOONIMATERJALIDE OMADUSTELE}

On uuritud mitmesuguseid erineva koosseisuga fosforit sisaldavate antipüreenidega modifitseeritud viskooskiude ja hinnatud nende toimet kompositsioonimaterjalide pőlevusele, suitsumoodustusele ja füüsikalis-mehhaanilistele omadustele. Pürolüüsgaasikromatograafiameetodil on määratud kergete pürolüüsiproduktide $\left(\mathrm{H}_{2} \mathrm{O}, \mathrm{CO}, \mathrm{CO}_{2}\right)$ eraldumistemperatuur erinevaid antipüreene sisaldavate viskooskiudude ja kompositsioonimaterjalide pürolüüsil. On toodud korrelatsioonid hapnikuindeksi ja dehüdratatsioonireaktsiooni parameetrite vahel ning selgitatud välja kốige perspektiivsema kompositsioonimaterjali koosseis.

S. VILKOVA, Serafima ARTYOMENKO, M. TYUGANOVA,

Aili KOGERMAN, O. KIRRET, E. HEINSOO

\section{EFFECT OF THE CHEMICAL COMPOSITION OF ANTIPYRENES PRESENT IN FLAMEPROOF VISCOSE FIBRES ON THE PROPERTIES OF COMPOSITE MATERIALS}

In this work different viscose fibres modified with phosphorus-containing antipyrenes as well as their effect on the flammability, smoke formation and physico-chemical properties of composite materials have been investigated.

By the pyrolysis gas chromatographic method antipyrene-containing viscose fibres and composite materials have been studied in order to identify light pyrolysis products $\left(\mathrm{H}_{2} \mathrm{O}, \mathrm{CO}, \mathrm{CO}_{2}\right)$ and establish their temperature dependence. The correlations between oxygen index and parameters of dehydration reactions are presented. The most advantageous composite materials have been defined. 